\section{Reducing the burden of injury}

Last month, the Institute of Medicine of the National Academy of Sciences issued a new report on the status and future of injury research, Reducing the Burden of Injury: Advancing Prevention and Treatment. ${ }^{1}$ In the pages of this journal, Baker recently discussed the importance to the field of the prior Institute of Medicine report, ${ }^{2}$ Injury in America. ${ }^{3}$ This report was precipitated in part by the crisis at the Centers for Disease Control and Prevention over firearm research, and in part by the perceived need to re-energize the field to accomplish the goals laid out in Injury in America. What does this report have to say about child and adolescent injury prevention, and what does it mean for ISCAIP?

While much of the report is fairly parochial to the United States, it does contain information and recommendations relevant to the field around the world. One very important issue addressed directly by the report is whether the field should legitimately include violence or whether it rightfully belongs to disciplines outside the injury field. This very issue was discussed by ISCAIP in Amsterdam at our meeting and by me previously in this column. ${ }^{4}$ The report concluded, as we have, that all injury prevention, including both intentional and unintentional injury, should be integrated into the same common framework of research. The inclusion of injuries regardless of intent in surveillance systems, the commonality of the agencies carrying out prevention, and the existence of risk factors which cut across intent argue strongly for inclusion of intentional injuries within the scope of injury research and prevention.

Unfortunately, the report in some ways muddies the waters of our field by rejecting the use of the term injury control. This term came about through the work of Haddon and his colleagues who sought to conceptually separate the injury producing event from the injury and its consequences. ${ }^{5}$ I have found it useful to think about how we might decrease morbidity and mortality from injury, or decrease its severity, even if we can't prevent the event of the injury itself. The report believes that these concepts are adequately covered with the use of the terms, "prevention" and "treatment".

The report recognizes the importance of injury surveillance for drawing attention to the magnitude of the injury problem, recognizing differences in injury rates between regions, and monitoring the impact of intervention programs. Key is uniform and reliable coding of both the external cause of injury as well as the nature of injury using the International Classification of Diseases (ICD) system. The 10th revision of ICD codes has been developed and released and is coming into widespread use around the world. There are substantial differences in particular between the 9th and 10th revisions on the classification of external cause of injuries. As an international society, ISCAIP members should urge adoption of ICD coding systems for all injury data in their countries, and for adequate training of coders in the new system. Many administrative databases contain data on injures, but are either not coded using the ICD convention or are only partly coded, that is they do not include codes for external cause of injures. We have found that the amount of effort and cost to add $\mathrm{E}$ codes to existing data collection efforts is minimal. ${ }^{6}$
The committee recognized the need, as has this journal, ${ }^{7}$ for injury research to be most effective it must be interdisciplinary, including disciplines of economics, psychology, engineering, law, and sociology as well as the more traditional injury disciplines of epidemiology, biomechanics, and medicine. There are very specific child needs in the contribution of some of these disciplines. For example, the report pointed out that "most knowledge of injury biomechanics is based on average-sized adults, and child injury ... assessment reference values are actually scaleddown estimates based on adult ..." (p 97). Many of the current problems with injury to children from airbags are due to the lack of regulations and standards which consider children, and lack of testing of these devices with child sized dummies. The lower use rate of most safety devices such as bike helmets and seat belts by adolescents compared with adults indicates the need for age specific studies and age specific interventions. Surprisingly, the committee discusses the need to do further research on the risk homeostasis theory despite little evidence that it really exists and lots of evidence that it doesn't.

All of the members of ISCAIP, as the members of this committee, are concerned about insuring that injury research be conducted as rigorously as possible, using the strongest possible research design. One method which the committee suggests to accomplish this is through increasing the funding for research training in injury prevention and control. This is an important recommendation because money for research and professional training is even more scarce in most countries than funding for injury research projects. Increases in funding for research will not accomplish the goal of advancing the injury field unless there are competent investigators to do the research and competent injury control professionals to implement the programs. Perhaps ISCAIP should work to obtain funds to support international injury research fellows in selected training sites around the world.

The report devotes a large chapter to a discussion of trauma care, which has traditionally been outside the purview of ISCAIP activities and this journal. Nevertheless, it is important to realize that in most parts of the world, including North America and Europe, organized systems of trauma care are the exception rather than the rule. Rapid transport of injured children and adolescents to appropriate medical centers where they can receive definitive care is an important and necessary part of injury control. The available data indicate that trauma systems can reduce death from injury by about $10 \%$.

Much of the last one third of the report is devoted to outlining a community, state, and federal response to the injury problem and to fostering collaboration between existing agencies. Much of this is specific to the US and not worth discussing here. However, some lessons are generalizable to other countries. The report points out that many efforts in communities and regions are uncoordinated and fragmented across non-governmental agencies, local government efforts, and regional offices. Most effective prevention programs are multifaceted and require the cooperation of individuals from multiple groups to implement successfully. I believe that early on in a program par- 
ticipants should recognize the relative ineffectiveness of their efforts if this cooperation does not occur.

Translating research into practice is another theme of the report, and one of the goals of our society and this journal. Systematic reviews such as those done by the Cochrane Injuries Review Group and by others have been critical in identifying interventions that are effective. Continued implementation of new research findings will require communication and collaboration across disciplines and national boundaries. Such efforts can and will be effective in ultimately reducing the burden of injury, especially for children and adolescents.

FREDERICK P RIVARA

Chair, ISCAIP

Harborview Injury Prevention and Research Center,

Box 359960, 325 Ninth Ave,
Seattle, WA98104, USA

(Tel: +1 206521 1530; fax: +1 206521 1562;

e-mail:fpr@u.washington.edu)

1 Bonnie RJ, Fulco CE, Liverman CT, eds. Reducing the burden of injury: advancing prevention and treatment. Washington, DC: National Academy Press, 1999

2 Baker S. The United States experience: injury in America. Inj Prev 1998;4(suppl):S4-6.

3 Committee on Trauma Research, Commission on Life Sciences, National Research Council and Institute of Medicine. Injury in America: a continuing public health problem. Washington, DC: National Academy Press, 1985.

4 Rivara FP. Injury research and violence: what's our contribution? Inj Prev 1996;2:249.

5 Haddon W Jr. On the escape of tigers: an ecologic note. Am f Public Health 1970;60:2229-34.

6 Rivara FP, Morgan P, Bergman AB, et al. Cost estimates for statewide reporting of injuries by E coding hospital discharge abstract data base systems. Public Health Rep 1990;105:635-8.

7 Pless IB. "Interdisciplinary" and "multidisciplinary" are not synonymous. Inj Prev 1995;1:65-6.

New smoke alarm law in Victoria

As of 1 February 1999 all homes in Victoria, Australia must have at least one smoke alarm. Since 1991 all new homes were required to have wired alarms-much preferable to those operated by batteries. The new law requires owners to install alarms in existing homes (retrofitting) and there is, at last, a significant penalty for non-compliance-a A $\$ 500$ fine. Going one step further, the 1999 law requires that houses undergoing alterations and needing a building permit must also have a battery operated alarm fitted before building work is approved. All public housing in Victoria also have alarms. The new legislation, combined with strong promotion by safety groups, will bring homes with alarms from $1 \%$ in 1991 to well over $80 \%$. The benefits are clear: the Victorian fire service estimates that between 1992 and 1997, 463 lives were saved by smoke alarms.

\section{Making child seat restraints more user friendly}

In January 1999 Department of Transport officials in the US and Canada announced that all new cars would be fitted with a uniform car seat anchoring system-similar to the ISOFIX attachments used in Europe. This is welcome news as it is certain to boost rates of proper use of these restraints. In the US only about $20 \%$ of children are in safety seats that are properly secured. Given the complexity of the task of fitting seats in some cars, this is a long overdue major step forward. It has been estimated that if all children were properly restrained (and in the rear of cars) about 70 lives would be saved in the US each year. Congratulations to transport officials for finally taking this welcome initiative.

\section{Smoking and injury fatalities}

A study published last year in Preventive Medicine (1998;27:871-8) found that smoking has "significant, consistent, dose-response, often strong and independent, prospective association with injury deaths internationally". (For readers not familiar with epidemiologic jargon, this string of terms is as close as we can get to saying that there is proof that smoking causes injuries.) This rather remarkable finding is based on a meta-analysis of six studies involving 10 cohorts in four countries. The mechanisms responsible for the effects are not easy to identify. Certainly, smoking causes fires and explosions and some children are poisoned by ingesting cigarettes. There is also evidence that smoking reduces the body's ability to avoid or survive injury. Smoking withdrawal is often accompanied by aggressiveness, confusion, and impulsivity. Once an injury occurs "smoking may increase the risk of serious complications and death" by impaired metabolism. The authors conclude: "Tobacco control is an injury control strategy practiced by many organizations and physicians. It seems prudent to warn the general population, smokers, physicians, and policy makers of smoking's associations with, and possibly immense contributions to, injuries". To which we can only add, "Amen". 